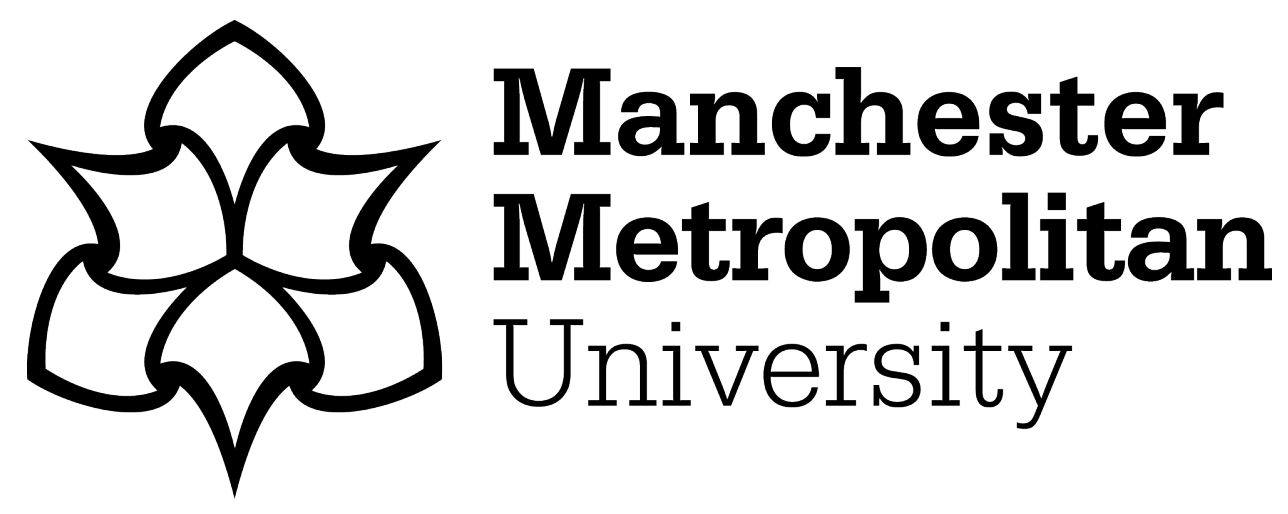

Elbardisy, Hadil M, García-Miranda Ferrari, Alejandro, Foster, Christopher W, Sutcliffe, Oliver B, Brownson, Dale AC, Belal, Tarek S, Talaat, Wael, Daabees, Hoda G and Banks, Craig E (2019) Forensic Electrochemistry: The Electroanalytical Sensing of Mephedrone Metabolites. ACS Omega, 4 (1). pp. 1947-1954. ISSN 2470-1343

Downloaded from: https://e-space.mmu.ac.uk/622362/

Version: Published Version

Publisher: American Chemical Society (ACS)

DOI: https://doi.org/10.1021/acsomega.8b02586

Usage rights: Creative Commons: Attribution-Noncommercial-No Derivative Works 4.0

Please cite the published version 


\title{
Forensic Electrochemistry: The Electroanalytical Sensing of Mephedrone Metabolites
}

\author{
Hadil M. Elbardisy, ${ }^{\dagger, \S}$ Alejandro García-Miranda Ferrari, ${ }^{\dagger}$ Christopher W. Foster, ${ }^{\dagger}$ \\ Oliver B. Sutcliffe, ${ }^{\dagger}+$ Dale A. C. Brownson, ${ }^{* \dagger}{ }^{\dagger}$ Tarek S. Belal, ${ }^{\perp}$ Wael Talaat, ${ }^{\S}$ Hoda G. Daabees, \\ and Craig E. Banks* ${ }^{\dagger}$ (i)
}

${ }^{\dagger}$ Faculty of Science and Engineering and ${ }^{\ddagger}$ MANchester DRug Analysis and Knowledge Exchange (MANDRAKE), Manchester Metropolitan University, Chester Street, Manchester M1 5GD, U.K.

${ }^{\S}$ Pharmaceutical Analysis Department, Faculty of Pharmacy and "Pharmaceutical Chemistry Department, Faculty of Pharmacy, Damanhour University, Damanhour 22511, Egypt

${ }^{\perp}$ Department of Pharmaceutical Analytical Chemistry, Faculty of Pharmacy, Alexandria University, Alexandria 21521, Egypt

\section{Supporting Information}

\begin{abstract}
The constant and persistent synthesis and abuse of new psychoactive substances have sparked the requirement for rapid, on-site, sensitive analytical protocols for their sensing and quantification. Mephedrone (4-MMC) is currently one of the most popular legal highs among recreational drug abusers and imposes a serious public health problem. In this paper, the electrochemical sensing of two metabolites of 4-MMC, namely, nor-mephedrone (4-methylcathinone, 4-MC) and dihydromephedrone (4-methylephedrine, 4-MMC-R), utilizing screen-printed graphite electrodes is performed. The accessible linear ranges by cyclic voltammetry were found to correspond to $40-300 \mu \mathrm{g} \mathrm{mL}^{-1}$ for $4-\mathrm{MC}$ in both phosphate buffer solution (PBS, $\mathrm{pH}$ 7.0) and spiked diluted human urine, whereas in the case of 4-MMC-R, the linearity ranges are $15-300 \mu \mathrm{g} \mathrm{mL}^{-1}$ (PBS, $\mathrm{pH} 3.0$ ) and $25-300 \mu \mathrm{g} \mathrm{mL}^{-1}$ (spiked diluted human urine). To maximize the assay sensitivity, differential pulse voltammetry (DPV) was performed toward the sensing of 4-MC, which exhibited a

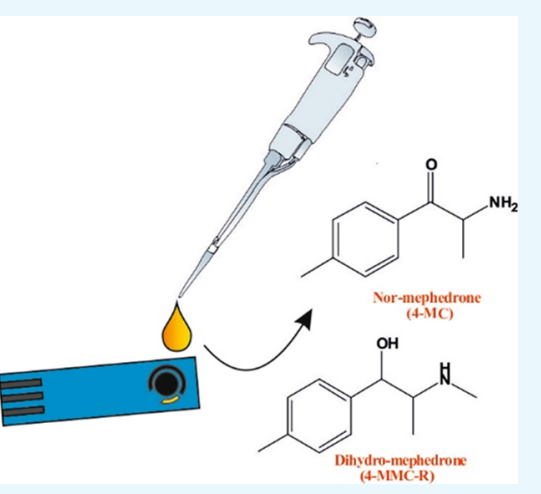
linear response over the range $10-250$ and $10-300 \mu \mathrm{g} \mathrm{mL}^{-1}$ in $\mathrm{PBS} \mathrm{pH} 7.0$ and spiked diluted human urine, respectively. However, 4-MMC-R demonstrated slightly higher sensitivity over the range $5-300 \mu \mathrm{g} \mathrm{mL}^{-1}$ in both PBS pH 3.0 and spiked diluted human urine. Using DPV, the limits of detection $(3 \sigma)$ were calculated and found to correspond to ca. 3.97 and $3.64 \mu \mathrm{g}$ $\mathrm{mL}^{-1}$ for 4-MC and 4-MMC-R (PBS, $\mathrm{pH} 7.0$ and 3.0), respectively, and ca. 6.34 and $3.87 \mu \mathrm{g} \mathrm{mL}^{-1}$ for 4-MC and 4-MMC-R (spiked diluted human urine), respectively. The potential interference of adulterants' metabolites commonly found in NPS street samples was also explored (at both $\mathrm{pH} 7.0$ and 3.0). The electrochemical approach reported herein provides a novel laboratory tool for the identification and quantification of synthetic cathinone metabolites and has potential for the basis of a portable analytical sensor for their fast, cheap, reliable, and accessible determination in the field.
\end{abstract}

\section{INTRODUCTION}

New psychoactive substances (NPS), typically referred to as "legal highs" or "designer drugs", are synthetic compounds that mimic the effects of common controlled substances but are not controlled under the Misuse of Drugs Act (1971). ${ }^{1}$ Worldwide, these NPS pose extensive problems for law enforcement agencies as well as public health officials, as they have triggered many serious public health implications typically ending with fatal repercussions. ${ }^{2}$ In 2013, the European Monitoring Centre for Drugs and Drug Addiction (EMCDDA) monitored more than 350 NPS appearing across Europe. ${ }^{3}$ In 2015, the EU Early Warning System (EU EWS) reported around 80000 seizures as a result of abuse of different kinds of NPS, of which synthetic cathinones (SC) contributed to $33 \%$ of the total NPS seizures. ${ }^{4}$ By the end of 2017, the number of NPS monitored by the EMCDDA reached over 670 according to their 2018 annual report. ${ }^{5}$ SC are structurally related to the natural stimulant
( \pm )-cathinone found in the leaves of the Khat plant (Catha edulis, a wild plant grown in the Horn of Africa and in the southwest Arabian Peninsula). ${ }^{6}$ SC possess amphetamine-like pharmacological properties and provide a cheap alternative to the phenethylamine class of psychoactive substances. ${ }^{6,7}$ One of the most popular and extensively abused SC in the recreational drug market is $( \pm)$-4-methyl- $N$-methylcathinone or $( \pm)$-mephedrone (4-MMC) (Scheme 1).

4-MMC was first synthesized by Sanchez in $1929,{ }^{8}$ however, the compound was ignored until its abuse in the early 2000s and used as a legal alternative to $( \pm)-3,4$-methylendioxymethampetamine (ecstasy) or cocaine. ${ }^{9}$ The first reported seizure from the abuse of 4-MMC was in Finland in 2007. ${ }^{10}$ In 2010, 4-MMC was

Received: September 29, 2018

Accepted: December 12, 2018

Published: January 25, 2019 
Scheme 1. Proposed Pathways for Phase I Metabolism of Mephedrone (4-MMC) ${ }^{19}$

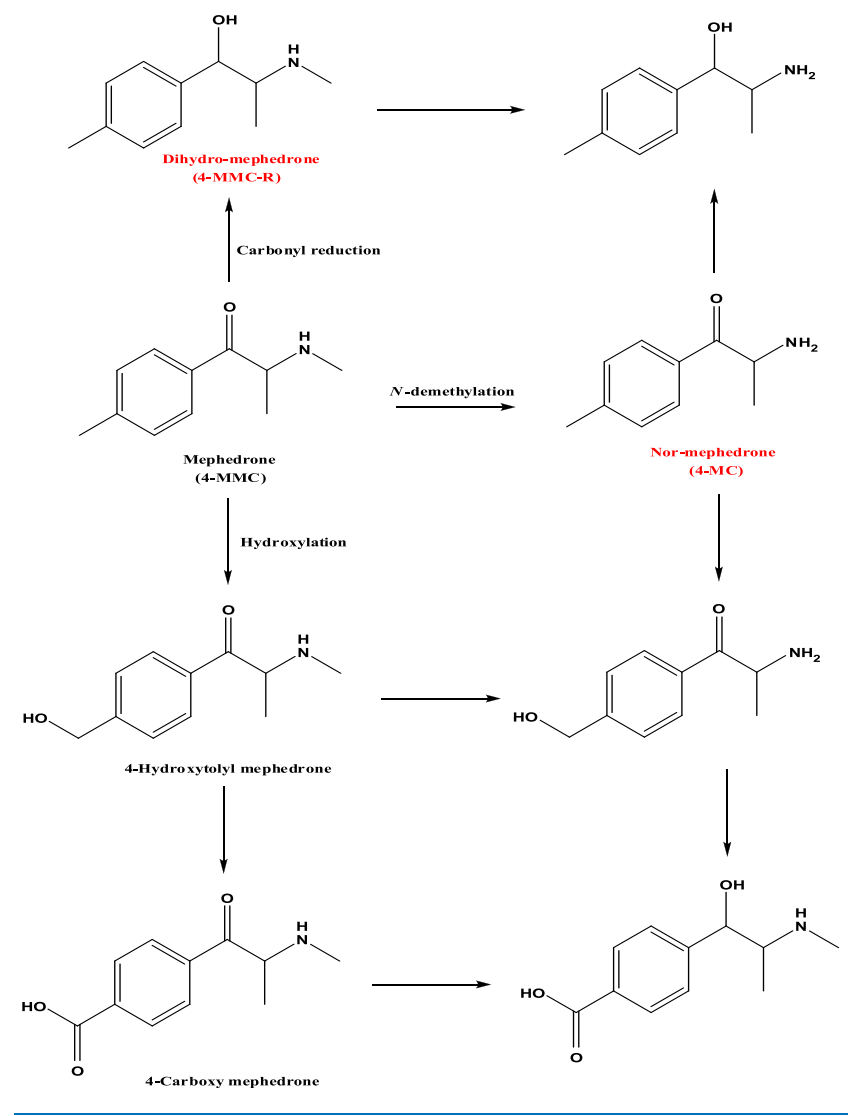

detected and seized in 28 European and neighboring countries, ${ }^{11}$ and it was the third commonly abused drug in the U.K. ${ }^{9}$ In April 2010, the U.K. controlled 4-MMC and listed it under class B substances in the Misuse of Drugs Act (1971). ${ }^{12}$ Similarly, the European Council, in December 2010, adopted a decision on submitting 4-MMC to control measures across the European Union. ${ }^{13}$ Later in 2012, the US classified 4-MMC as a "Schedule I drug" under the Synthetic Drug Abuse Prevention Act of 2012. ${ }^{14}$ Despite the legislative constraints imposed in 2010 and 2012, many 4-MMC related fatalities have been reported afterward. ${ }^{15-17}$ Therefore, the need to develop a rapid, cost-effective, on-site detection strategy is crucial for law enforcement officials. 4-MMC undergoes extensive metabolism upon its administration, giving rise to several metabolites (phase I and phase II metabolites). ${ }^{18}$ Many of these metabolites have been described both in vitro ${ }^{19,20}$ and in vivo, in humans. ${ }^{18}$ The postulated phase I metabolic pathways were as follows (Scheme 1): (i) $\mathrm{N}$-demethylation of the primary amine to form normephedrone (4-methylcathinone, 4-MC), (ii) reduction of the $\beta$-keto moiety to the respective alcohol named dihydromephedrone (4-methylephedrine, 4-MMC-R), (iii) oxidation of the tolyl moiety to the corresponding alcohol, 4-hydroxytolylmephedrone, which undergoes further oxidation to the respective carboxylic acid, termed as 4-carboxymephedrone. ${ }^{18,19,21}$ Although many reports adopted the pharmacokinetic study of 4-MMC, only one paper published the approximate concentrations of 4-MMC metabolites excreted in human urine as follows: (i) unchanged $4-\mathrm{MMC} \%$ recovered in urine $=1.15 \%$ of the ingested 4-MMC dose, (ii) 4-MC \% = 10\% of total 4-MMC excreted in urine, (iii) 4-MMC-R $\%=20 \%$ of total 4-MMC excreted in urine, (iv) 4-carboxymephedrone $\%=$ major metabolite in urine, exists as 10 times the amount of 4-MMC excreted in urine. ${ }^{22}$ As described in (Table 1), typical quantification of 4-MMC metabolites is via liquid chromatography mass spectrometry (LC/MS $)^{23-26}$ and gas chromatography mass spectrometry (GC/MS). ${ }^{27,28}$ Therefore, upon consultation of the literature, it is apparent that all of the current developed methods, for the quantification of 4-MMC metabolites, cannot be utilized as a low-cost, portable sensing platform.

Forensic electrochemistry has been extensively reported as an advantageous analytical tool that is adaptable to hand-held devices, in light of its portability, sensitivity, and selectivity. ${ }^{29,30}$ Screen-printed graphite electrodes (SPEs) are useful analytical platforms within forensic electrochemistry and have been regularly applied for the electrochemical quantification of a range of target analytes, ${ }^{31,32}$ given that they enable the translation of laboratory experiments into the "field" due to their portability, low cost, easy to use, and disposable nature that render them the sensors of choice for on-site detection of drugs of abuse by police officers and forensic analysts. Consequently, the electrochemical sensing of 4-MMC metabolites (4-MC and 4-MMC-R) is reported for the first time utilizing disposable SPEs. The proposed protocol has been validated in both ideal buffer solutions as well as in spiked diluted human urine by using both cyclic voltammetry (CV) and differential pulse voltammetry (DPV). Additionally, the metabolites of the 4-MMC adulterants (that are typically found in street samples) are electrochemically characterized for their potential interference in the simultaneous sensing of 4-MC and 4-MMC-R. To the best of our knowledge, no established on-site portable methodology has been developed for the quantification of 4-MMC metabolites: 4-MC and 4-MMC-R.

\section{RESULTS AND DISCUSSION}

The electrochemical sensing of mephedrone metabolites, 4-MC and 4-MMC-R, is reported for the first time utilizing disposable graphite screen-printed electrodes (SPEs). First, the effects of the buffer $\mathrm{pH}$ and applied voltammetric scan rate were explored and analyzed to find the optimal analytical signal/voltammetric output; these data are presented in detail within the Supporting Information (SI). Briefly, the optimum $\mathrm{pH}$ values for the electrochemical reduction of 4-MC and electrochemical oxidation of 4-MMC-R within a phosphate buffer solution (PBS) were found to correspond to $\mathrm{pH} 7.0$ and 3.0, respectively (Figures S1 and S2). Additionally, analysis of peak potential vs $\mathrm{pH}$ indicates gradient values close to that expected for a oneproton and two-electron process $\left(33 \mathrm{mV}\right.$ per $\mathrm{pH}$ unit at $\left.25^{\circ} \mathrm{C}\right)$ for both metabolites. The effect of voltammetric scan rate $(v)$ upon the electrochemical response of both metabolites was also studied (see SI), indicating that the electrochemical detection of both metabolites undergoes diffusion controlled processes (Figures S3 and S4). Next, cyclic voltammetric measurements were performed using graphite screen-printed electrodes (SPEs) for the analyses of 4-MC and 4-MMC-R in 0.1 M PBS at pH 7.0 and 3.0, respectively. It is important to note that in all cases, a new SPE was used for each analytical scan/detection showing the real benefit of SPEs.

Figure 1 depicts the cyclic voltammetric signatures of both 4MC (Figure 1A) and 4-MMC-R (Figure 1B) where the electrochemical reduction and oxidation peaks are observed at peak potentials $\left(E_{\mathrm{p}, \text { red }} / \mathrm{V}\right) \approx-1.56 \mathrm{~V}$ and $\left(E_{\mathrm{p}, \mathrm{ox}} / \mathrm{V}\right) \approx+0.91 \mathrm{~V}$, for 4-MC and 4-MMC-R, respectively. The electroanalytical quantification of the metabolites is next considered and 
离

产

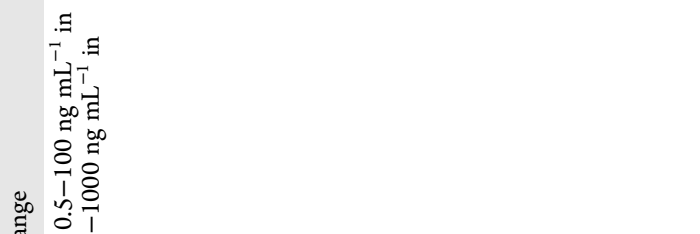

茫

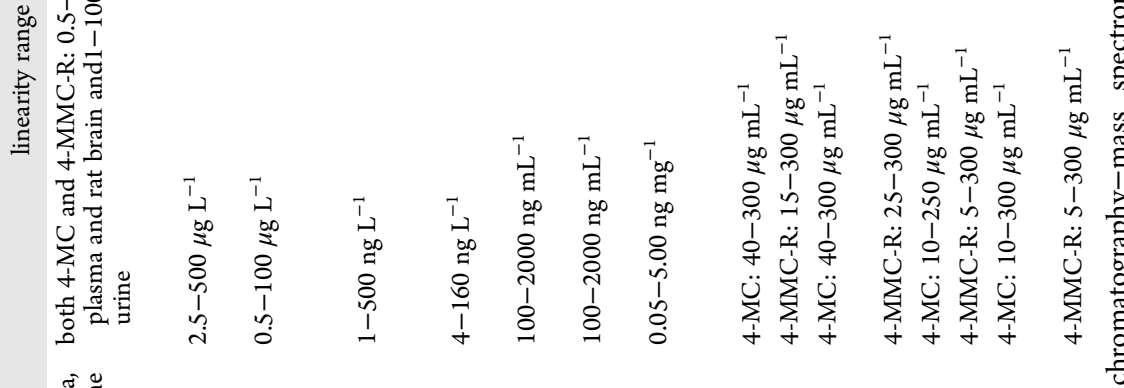

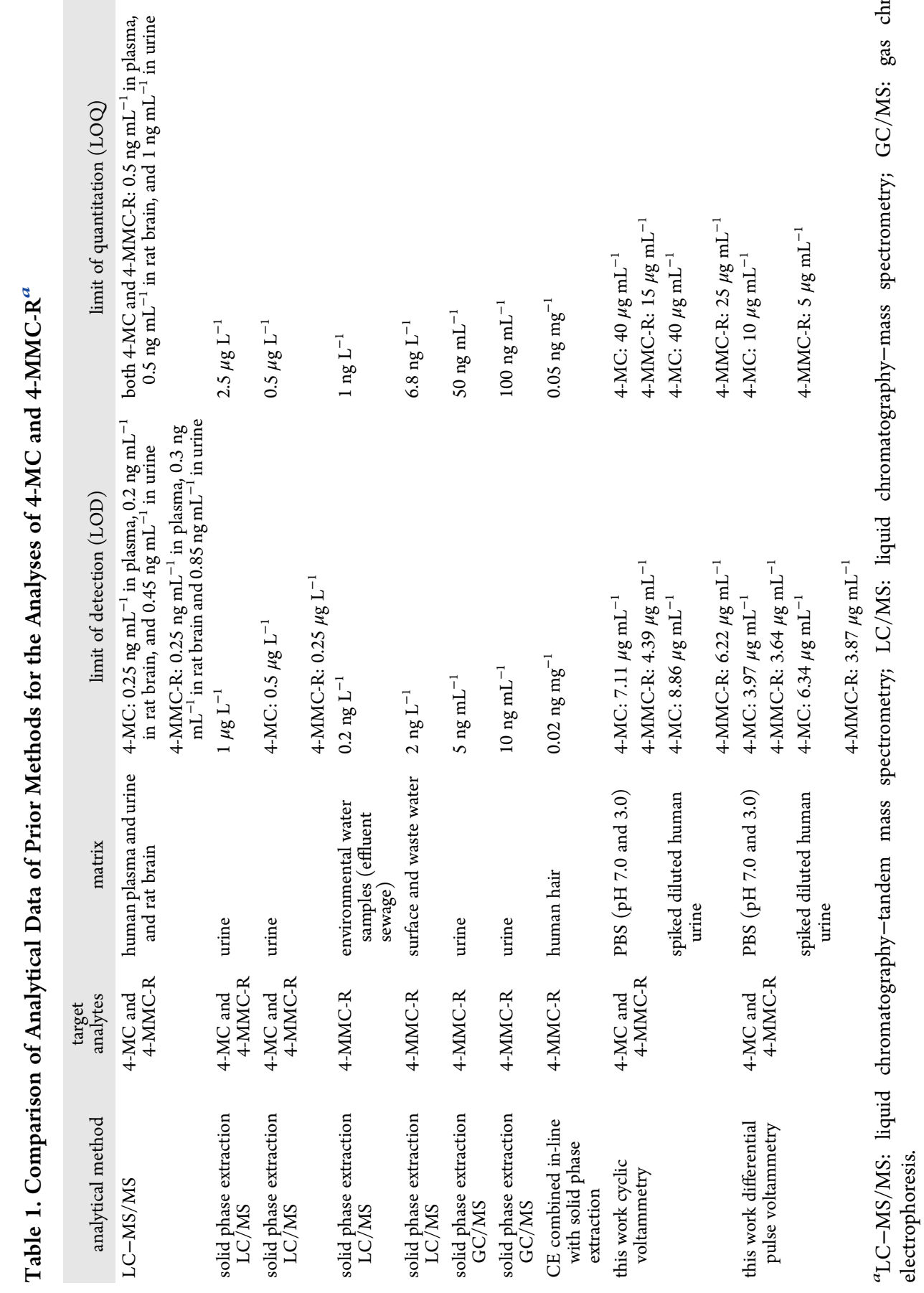

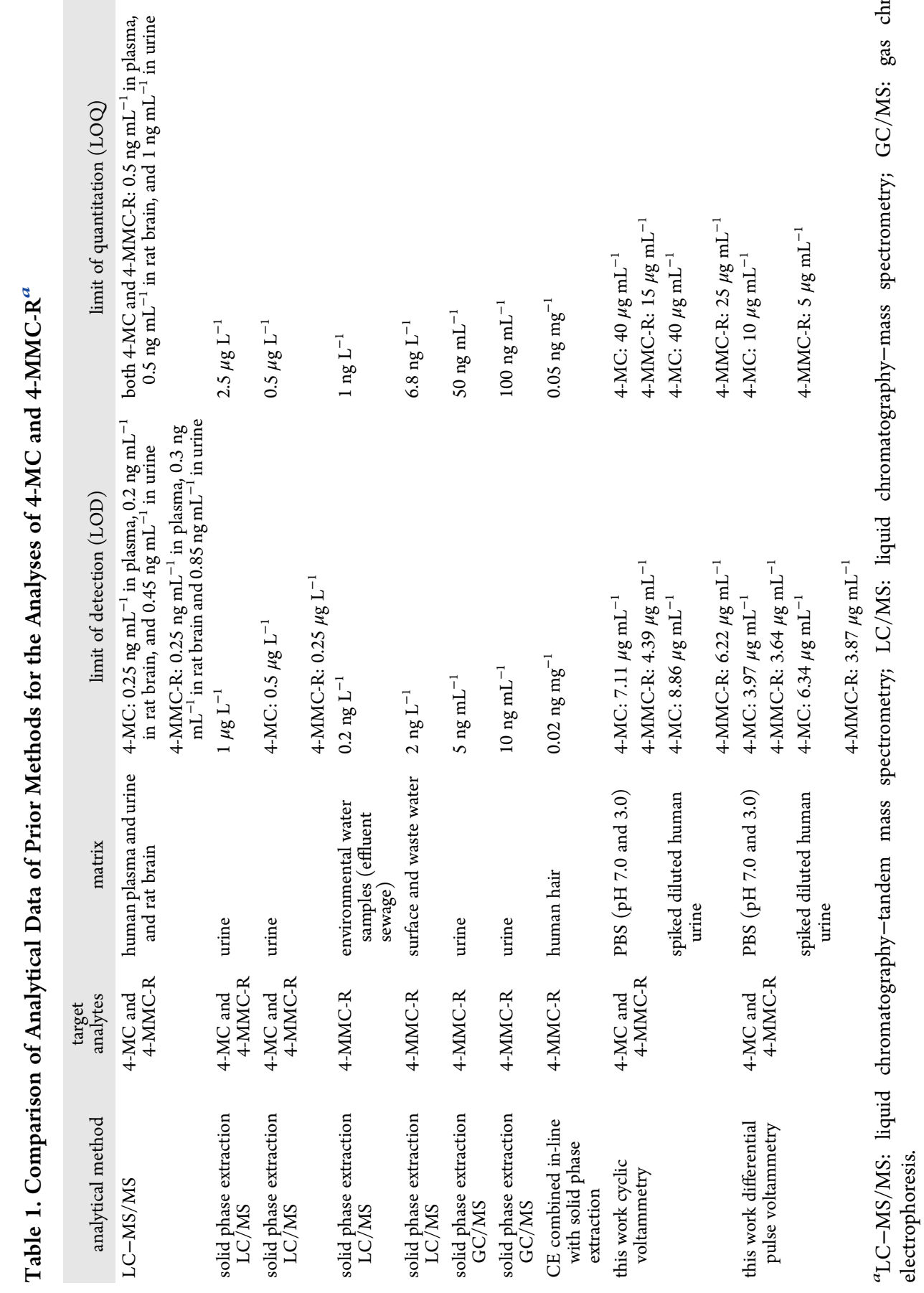

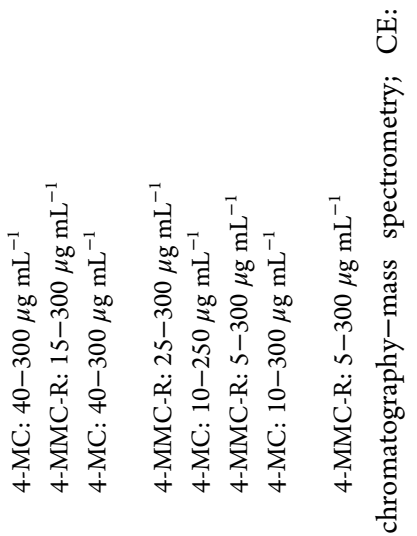


A

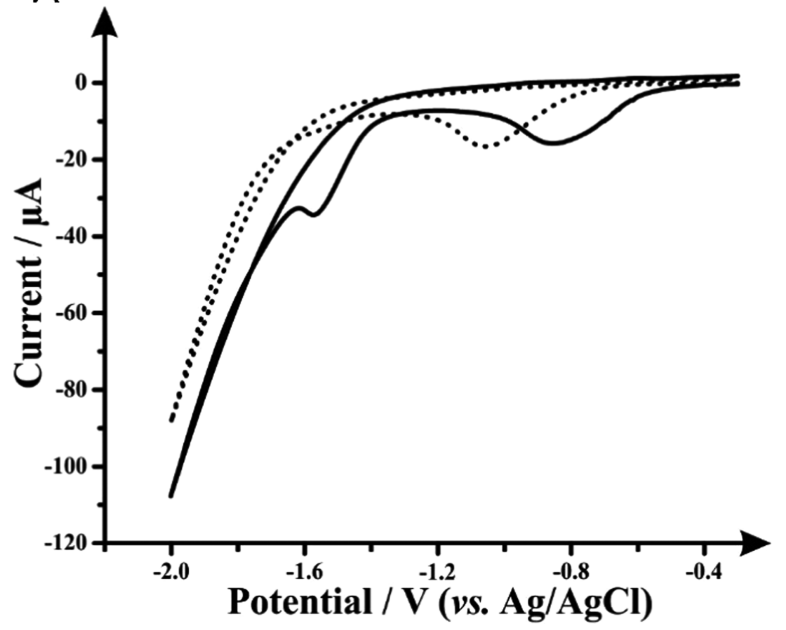

B

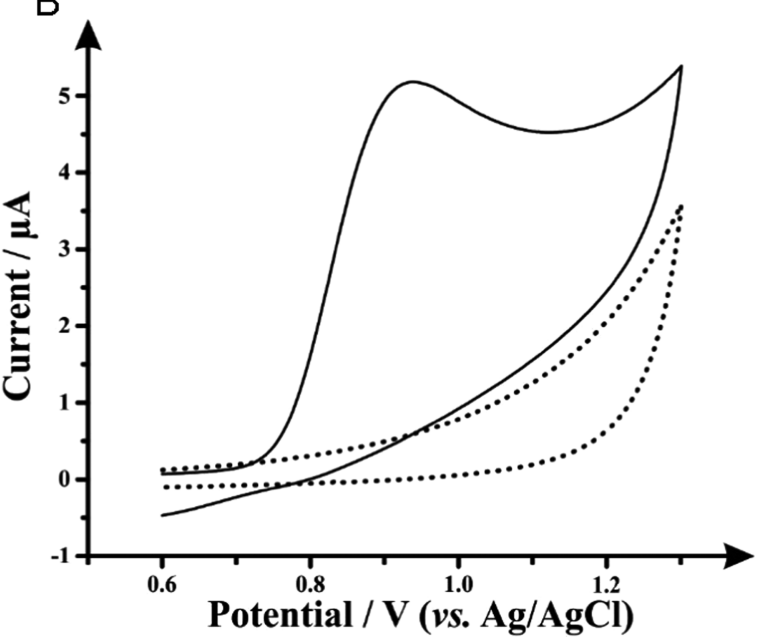

Figure 1. Cyclic voltammetric profiles obtained using graphite screen-printed electrodes (SPEs) in: (A) PBS buffer (0.1 M, pH 7.0) in the presence (solid line) and in absence (dotted line) of $200 \mu \mathrm{g} \mathrm{mL}^{-1}$ of 4-MC, (B) PBS buffer (0.1 M, pH 3.0) in the presence (solid line) and in absence (dotted line) of $100 \mu \mathrm{g} \mathrm{mL}^{-1}$ of 4-MMC-R. Scan rate: $50 \mathrm{mV} \mathrm{s}^{-1}$ (vs Ag/AgCl). Note in all cases, each plot/voltammogram is a new SPE.

validated according to the International Conference on Harmonization guidelines. Cyclic voltammetric and differential pulse voltammetric measurements were next performed in $0.1 \mathrm{M}$ PBS, using $\mathrm{pH} 7.0$ and 3.0 for the quantitation of 4-MC and 4MMC-R (Figures 2 and 3). A series of increasing concentrations were analyzed for each metabolite using cyclic voltammetry and differential pulse voltammetry, and calibration plots were constructed for 4-MC and 4-MMC-R. Upon the application of cyclic voltammetry, it was deduced that 4-MC exhibits a linear plot over the concentration range $40-300 \mu \mathrm{g} \mathrm{mL}{ }^{-1}$, the regression equation was: $I_{\mathrm{p}}(\mu \mathrm{A})=-0.9336 \mu \mathrm{A}-0.0344 \mu \mathrm{A} / \mu \mathrm{g}$ $\mathrm{mL}^{-1}, R^{2}=0.999$ (inset Figure $2 \mathrm{~A}$ ). The limit of detection (LOD) was calculated using the formula $3 \mathrm{Sa} / b$ (where " $\mathrm{Sa}$ " is the standard deviation of the intercept of the calibration curve and " $b$ " is the slope of the calibration curve), and it corresponds to $7.11 \mu \mathrm{g} \mathrm{mL}^{-1}$. Likewise, upon quantification of 4-MMC-R by cyclic voltammetry, a calibration plot was generated in the linear range $15-300 \mu \mathrm{g} \mathrm{mL}^{-1}$; with regression equation: $I_{\mathrm{p}}(\mu \mathrm{A})=$ $-0.3443 \mu \mathrm{A}+0.0314 \mu \mathrm{A} / \mu \mathrm{g} \mathrm{mL}^{-1}, R^{2}=0.999$ (inset Figure $2 \mathrm{~B}$ ). The LOD was calculated using the same formula previously described, and it corresponds to $4.39 \mu \mathrm{g} \mathrm{mL}^{-1}$. However, the sensitivity and the detection limits were slightly enhanced by the application of differential pulse voltammetry, where 4-MC was found to be linear in the range $10-250 \mu \mathrm{g} \mathrm{mL}^{-1}$; with regression equation: $I_{\mathrm{p}}(\mu \mathrm{A})=-0.6101 \mu \mathrm{A}-0.0603 \mu \mathrm{A} / \mu \mathrm{g} \mathrm{mL}^{-1}, R^{2}=$ 0.999 (inset Figure $3 \mathrm{~B}$ ), and the calculated LOD is equivalent to $3.97 \mu \mathrm{g} \mathrm{mL}^{-1}$. In case of 4-MMC-R, it exhibits a linear response over the concentration range $5-300 \mu \mathrm{g} \mathrm{mL}^{-1}$; with regression equation: $I_{\mathrm{p}}(\mu \mathrm{A})=-0.0214 \mu \mathrm{A}+0.031 \mu \mathrm{A} / \mu \mathrm{g} \mathrm{mL}^{-1}, R^{2}=$ 0.999 (inset Figure $3 \mathrm{~B}$ ), and the calculated LOD is equivalent to $3.64 \mu \mathrm{g} \mathrm{mL}^{-1}$.

Precision, robustness, and selectivity studies are included in the Supporting Information, exhibiting a good reproducibility when using a new SPE for each sample/test. Selectivity studies were performed using the metabolites of common adulterants present in street samples, benzocaine, caffeine and paracetamol finding that none of them interferes in the electrochemical reduction of 4-MC, and only the paracetamol metabolite $\beta$-Dglucuronide demonstrated an oxidation peak in the positive potential window that could potentially interfere with the electrochemical oxidation of 4-MMC-R.

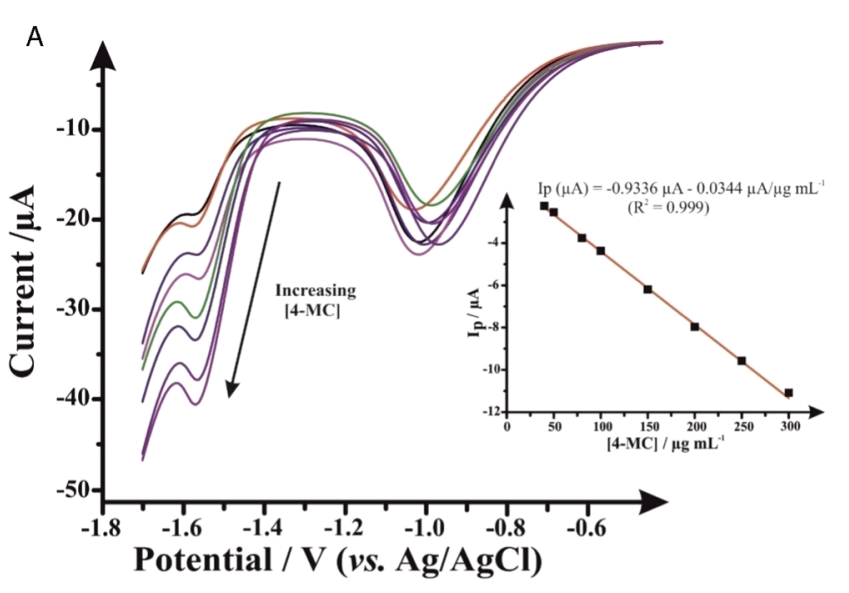

B

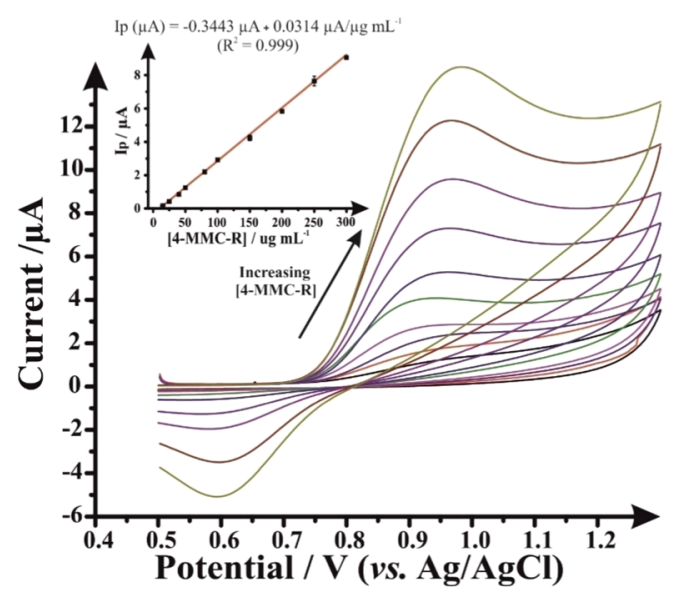

Figure 2. (A) Cyclic voltammograms using SPEs in 0.1 M PBS buffer $(\mathrm{pH} 7.0)$ as a result of increasing concentrations of 4-MC $(40-300 \mu \mathrm{g}$ $\mathrm{mL}^{-1}$ ). Inset: corresponding analytical calibration plot of $I_{\mathrm{p}}$ vs 4-MC concentration; scan rate: $50 \mathrm{mV} \mathrm{s}^{-1}$ (vs $\mathrm{Ag} / \mathrm{AgCl}$ ). (B) Cyclic voltammograms using SPEs in $0.1 \mathrm{M}$ PBS buffer ( $\mathrm{pH} 3.0)$ as a result of increasing concentrations of 4-MMC-R $\left(15-300 \mu \mathrm{g} \mathrm{mL}^{-1}\right)$. Inset: corresponding analytical calibration plot of $I_{\mathrm{p}}$ vs 4-MMC-R concentration; scan rate: $50 \mathrm{mV} \mathrm{s}^{-1}$ (vs Ag/AgCl).

Analytical Application (Application of the Method to Spiked Diluted Human Urine). To evaluate the analytical 

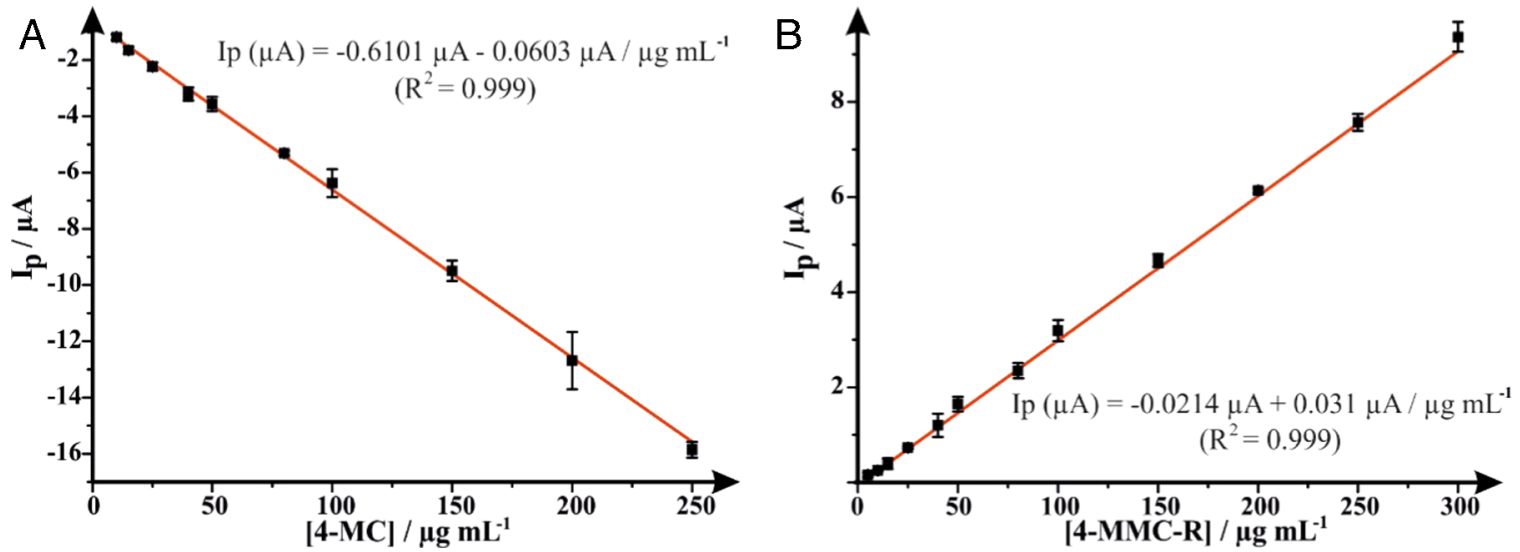

Figure 3. (A) Plot of peak current $\left(I_{\mathrm{p}}\right)$ as a function of $4-\mathrm{MC}$ in concentration range $10-250 \mu \mathrm{g} \mathrm{mL}^{-1}$ in $0.1 \mathrm{M}$ PBS (pH 7.0) using differential pulse voltammetry. (B) Plot of peak current $\left(I_{\mathrm{p}}\right.$ ) as a function of 4-MMC-R in concentration range $5-300 \mu \mathrm{g} \mathrm{mL}^{-1}$ in $0.1 \mathrm{M} \mathrm{PBS}$ (pH 3.0) using differential pulse voltammetry. Modulation amplitude: $0.1 \mathrm{~V}$; modulation time: $0.02 \mathrm{~s}$; interval time: $0.1 \mathrm{~s}$; step: $0.005 \mathrm{~V}$; scan rate: $50 \mathrm{mV} \mathrm{s} \mathrm{s}^{-1}$ (vs Ag/ $\mathrm{AgCl}$ ).
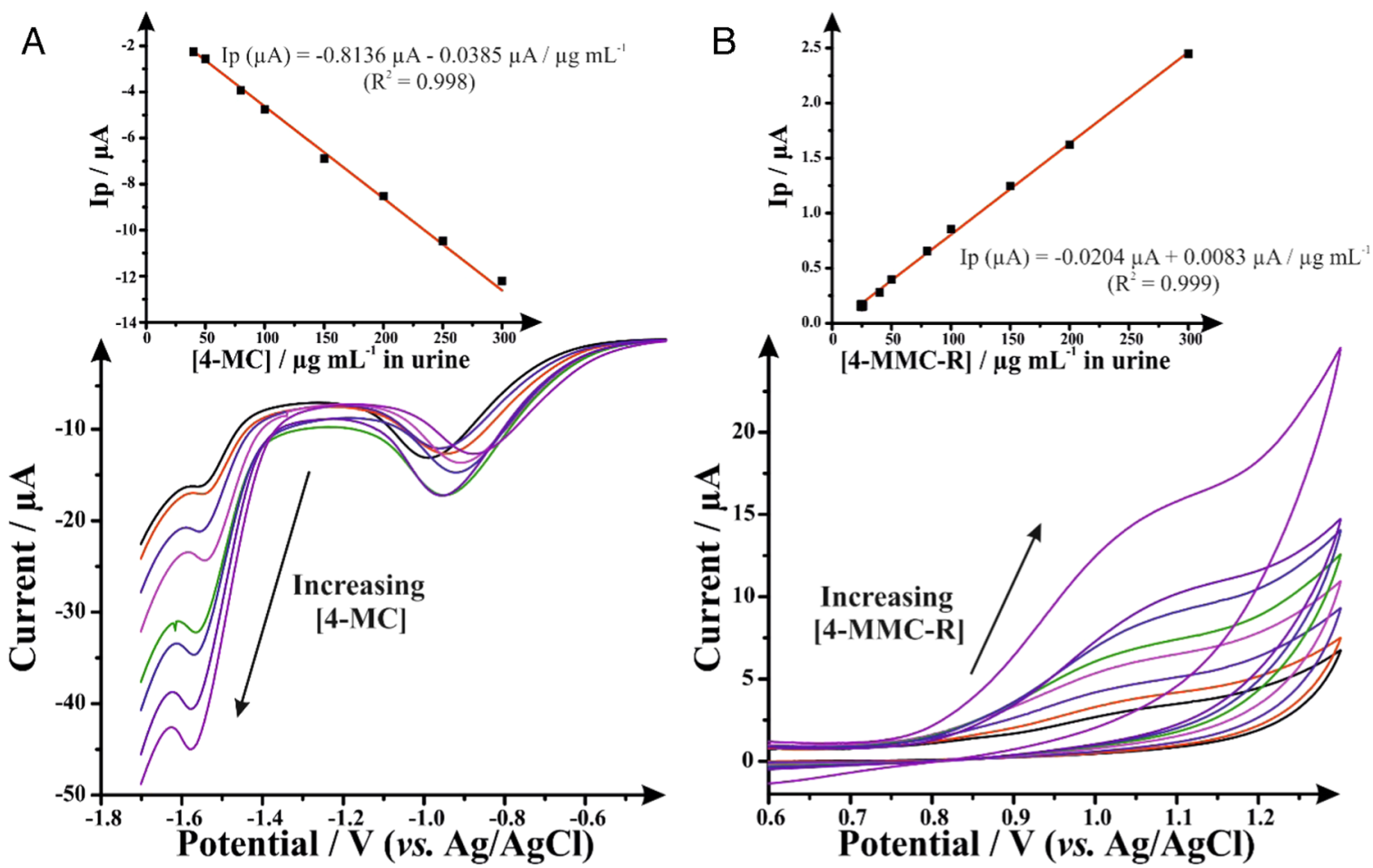

Figure 4. (A) Cyclic voltammograms using SPEs in human urine spiked with different concentrations of 4-MC $\left(40-300 \mu \mathrm{g} \mathrm{mL}^{-1}\right)$. Inset: corresponding analytical calibration plot of $I_{\mathrm{p}}$ vs 4-MC concentration; scan rate: $50 \mathrm{mV} \mathrm{s}^{-1}$ (vs Ag/AgCl). (B) Cyclic voltammograms using SPEs in human urine spiked with different concentrations of 4-MMC-R $\left(25-300 \mu \mathrm{g} \mathrm{mL}^{-1}\right)$. Inset: corresponding analytical calibration plot of $I_{\mathrm{p}}$ vs 4-MMC-R concentration; scan rate: $50 \mathrm{mV} \mathrm{s}^{-1}$ (vs $\mathrm{Ag} / \mathrm{AgCl}$ ).

applicability of the developed methods, calibration curves were constructed for both 4-MC and 4-MMC-R, in spiked diluted human urine samples using both cyclic voltammetry and differential pulse voltammetry. Using cyclic voltammetry, 4$\mathrm{MC}$ and 4-MMC-R exhibit a linear behavior over the concentration range $40-300$ and $25-300 \mu \mathrm{g} \mathrm{mL}^{-1}$, respectively. The linear regression equations can be represented as: $I_{\mathrm{p}}(\mu \mathrm{A})=$ $-0.8136 \mu \mathrm{A}-0.0385 \mu \mathrm{A} / \mu \mathrm{g} \mathrm{mL}^{-1} ; R^{2}=0.998$ (Figure 4A) and $I_{\mathrm{p}}(\mu \mathrm{A})=-0.0204 \mu \mathrm{A}+0.0083 \mu \mathrm{A} / \mu \mathrm{g} \mathrm{mL}^{-1} ; R^{2}=0.999$ (Figure $4 \mathrm{~B})$, for 4-MC and 4-MMC-R, respectively. The LOD (calculated as above) were found to correspond to 8.86 and $6.22 \mu \mathrm{g} \mathrm{mL}^{-1}$ for 4-MC and 4-MMC-R, respectively, which are in agreement with the figures computed when validating the two metabolites in buffer solutions. The detection limits were slightly enhanced upon the application of DPV, where 4-MC and 4-MMC-R were found to be linear over the concentration range $10-300$ and $5-300 \mu \mathrm{g} \mathrm{mL}^{-1}$, respectively. The corresponding regression equations and the calculated LOD are: $I_{\mathrm{p}}(\mu \mathrm{A})=-0.6236 \mu \mathrm{A}-0.0384 \mu \mathrm{A} / \mu \mathrm{g} \mathrm{mL}^{-1} ; R^{2}=0.998$, $\mathrm{LOD}=6.34 \mu \mathrm{g} \mathrm{mL}^{-1}$ for 4-MC (Figure 5A) and $I_{\mathrm{p}}(\mu \mathrm{A})=$ $0.1582 \mu \mathrm{A}+0.0359 \mu \mathrm{A} / \mu \mathrm{g} \mathrm{mL}{ }^{-1} ; R^{2}=0.999, \mathrm{LOD}=3.87 \mu \mathrm{g}$ $\mathrm{mL}^{-1}$ for 4-MMC-R (Figure 5B), for 4-MMC-R. The aforementioned validation data obtained from spiked diluted human urine demonstrated that the developed electrochemical sensing methodologies can held a great promise for the reliable and sensitive quantitations of 4-MC and 4-MMC-R in the clinical analysis. 

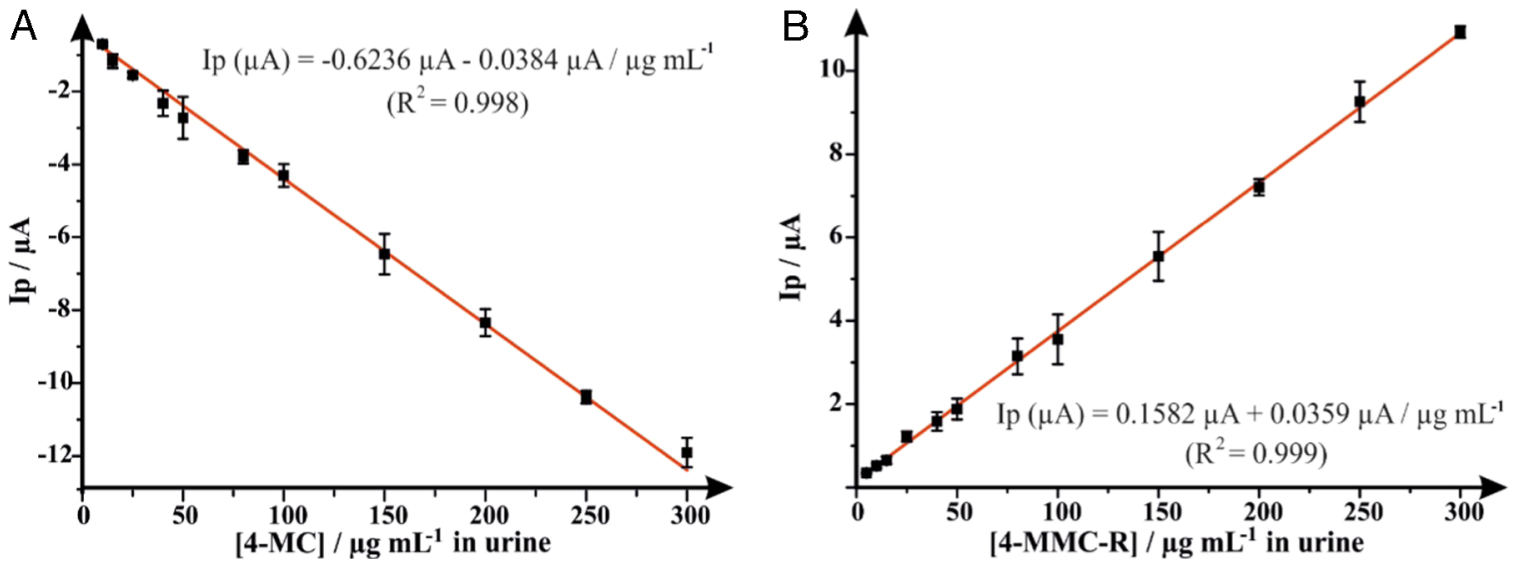

Figure 5. (A) Plot of peak current $\left(I_{\mathrm{p}}\right)$ as a function of 4-MC in concentration range $10-300 \mu \mathrm{g} \mathrm{mL}^{-1}$ in human urine using differential pulse voltammetry. (B) Plot of peak current $\left(I_{\mathrm{p}}\right)$ as a function of 4-MMC-R in concentration range $5-300 \mu \mathrm{g} \mathrm{mL} \mathrm{L}^{-1}$ in human urine using differential pulse voltammetry. Modulation amplitude: $0.1 \mathrm{~V}$; modulation time: $0.02 \mathrm{~s}$; interval time: $0.1 \mathrm{~s}$; step: $0.005 \mathrm{~V}$; scan rate: $50 \mathrm{mV} \mathrm{s} \mathrm{s}^{-1}$ (vs Ag/AgCl).

\section{CONCLUSIONS}

For the first time, the electrochemical detection of mephedrone metabolites, namely nor-mephedrone (4-MC) and 4-methylephedrine (4-MMC-R), was found to be viable via the use of graphite SPEs in both model buffer solutions and diluted human urine using CV and DPV. The applied methodologies are simple, reliable, rapid, and sensitive; where the differential pulse voltammetric measurements offered a limit of detection (LOD, $3 \sigma$ ) of 3.97 and $3.64 \mu \mathrm{g} \mathrm{mL}{ }^{-1}$ for 4-MC and 4-MMC-R, respectively, in the buffer solution and 6.34 and $3.87 \mu \mathrm{g} \mathrm{mL}^{-1}$ for 4-MC and 4-MMC-R, respectively, in spiked diluted human urine samples. To date, current employed methods for the detection and quantification of these substances rely on the use of mass detectors that are expensive and cannot be tailored for on-site screening. However, the reported electrochemical protocols benefit from the portable and disposable nature of SPEs. The metabolites of adulterants, likely to be found in "legal high" street samples, paracetamol $\beta$-D-glucuronide, 1-methyluric acid, and 4-acetamidobenzoic acid, have also been explored at the optimum $\mathrm{pH}$ buffer using cyclic voltammetry. In PBS buffer $\mathrm{pH}$ 3.0, there is no electrochemical selectivity over the electrochemical detection of 4-MMC-R in the presence of paracetamol $\beta$-D-glucuronide, however, this interference was not visible upon 4-MC determination. Future work is directed to overcome this limiting issue of overlapping voltammetric waves using high-performance liquid chromatography with an electrochemical detector.

Experimental Section. All chemicals were of pure analytical grade (obtained from Sigma-Aldrich Co. Ltd., Gillingham, U.K.) and were used as received without any further purification. All solutions were prepared with Milli-Q deionized water with a resistivity of no less than $18.2 \Omega \mathrm{cm}^{-1}$ (Millipore system). All solutions (unless stated otherwise) were vigorously degassed for 10 min with high purity nitrogen to remove oxygen prior to analysis. Samples of mephedrone (4-MMC) and its metabolites (nor-mephedrone, 4-MC and 4-methylephedrine, 4-MMC-R) were prepared, under U.K. Home Office Drug Licence (No. 337201), as their corresponding hydrochloride salts at Manchester Metropolitan University. The synthesis of the racemic target compounds was achieved using the previously reported method by Mayer et al. ${ }^{33}$ in 15\% (4-MMC and 4-MMC-R) $37 \%$ (4-MC) overall yield. The hydrochloride salts were obtained as stable, off-white powders and determined to be soluble $\left(10 \mathrm{mg} \mathrm{mL}^{-1}\right)$ in deionized water, methanol, and dimethylsulfoxide. To ensure the authenticity of the materials utilized in this study, the synthesized samples were fully structurally characterized by ${ }^{1} \mathrm{H} \mathrm{NMR},{ }^{13} \mathrm{C}$ NMR, GC-MS, and ATR-FTIR, and the purity of all samples confirmed by elemental analysis ( $>99.6 \%$ in all cases). ${ }^{33}$

Voltammetric measurements were conducted using a " $\mu$ Autolab type III" (Metrohm Autolab, The Netherlands) potentiostat/galvanostat interfaced to a PC loaded with NOVA 2.1 software. All measurements were carried out using graphite screen-printed macroelectrodes (SPEs) (with the dimensions of $41 \mathrm{~mm}$ long $\times 7 \mathrm{~mm}$ wide) that comprise of a three-electrode configuration with a $3.1 \mathrm{~mm}$ diameter graphite working electrode, a graphite counter and a $\mathrm{Ag} / \mathrm{AgCl}$ reference electrode. The SPEs were fabricated in house at Manchester Metropolitan University (MMU) have been previously characterized ${ }^{34,35}$ and are incorporated into an "edge connector" to accommodate the SPE while electrically connected to the potentiostat as previously reported. ${ }^{36,37}$ Voltammetric measurements were carried out upon applying $30 \mu \mathrm{L}$ of solution by micropipette onto the electrode surface, such that the three partitions are covered with solution. Note that a new/separate SPE was used for each voltammogram acquired, and all measurements were conducted at ambient temperature.

Preparation of the metabolites standard stock solutions, calibration curve working standard solutions, and selectivity standards are described in details in the Supporting Information (SI).

Application of the Method to Biological Samples (Spiked Diluted Human Urine Samples). For the application of the biological sample, fresh urine samples were collected from healthy volunteers on the same day of the experiments. All experiments were performed in accordance with the applicable laws and formal rules, and the official ethics committees have approved these experiments. Urine sample $(10.0 \mathrm{~mL})$ was added separately to two $200.0 \mathrm{~mL}$ glass volumetric flasks, one flask was made to the mark with $0.1 \mathrm{M}$ PBS buffer $\mathrm{pH} 7.0$ (Solution 1) and the other was made to volume with $0.1 \mathrm{M}$ PBS buffer $\mathrm{pH} 3.0$ (Solution 2). Solution 1 and Solution 2 were used to prepare $1 \mathrm{mg} \mathrm{mL}^{-1}$ of 4-MC and 4MMC-R standard stock solutions, respectively. Thereafter, two separate sets of $5.0 \mathrm{~mL}$ volumetric flasks were spiked with different volumes of 4-MC and 4-MMC-R standard stock solutions, and the flask set containing 4-MC was completed to 
volume with Solution 1, whereas the other flask set containing 4MMC-R was completed to the mark with Solution 2. All of the solutions were degassed for $10 \mathrm{~min}$ with highly pure nitrogen, with the voltammetric measurements (CV and DPV) being carried out directly without any further pretreatment.

\section{ASSOCIATED CONTENT}

\section{S Supporting Information}

The Supporting Information is available free of charge on the ACS Publications website at DOI: 10.1021/acsomega.8b02586.

Preparation of standard stock solutions and calibration curve working standard solutions for cyclic voltammetry $(\mathrm{CV})$ and differential pulse voltammetry (DPV); preparation of selectivity standards; effect of voltammetric scan rate $(v)$ on the electrochemical response of mephedrone metabolites; effect of 0.1 M PBS buffer on the reduction; effect of $0.1 \mathrm{M}$ PBS buffer on the oxidation; cyclic voltammograms; voltammetric profiles (PDF)

\section{AUTHOR INFORMATION}

\section{Corresponding Authors}

*E-mail: d.brownson@mmu.ac.uk. Tel: ++(0)1612476561 (D.A.C.B.).

*E-mail: c.banks@mmu.ac.uk. Tel: ++(0)1612471196. Fax: + $+(0) 1612476831$. Web: www.craigbanksresearch.com (C.E.B.).

\section{ORCID $\odot$}

Christopher W. Foster: 0000-0002-5487-2803

Oliver B. Sutcliffe: 0000-0003-3781-7754

Craig E. Banks: 0000-0002-0756-9764

Notes

The authors declare no competing financial interest.

\section{REFERENCES}

(1) Cahal, D. A. Misuse of Drugs Regulations 1973. Br. Med. J. 1974, 1, $70-72$.

(2) Hillebrand, J.; Olszewski, D.; Sedefov, R. Legal highs on the Internet. Subst. Use Misuse 2010, 45, 330-340.

(3) European Drug Report 2014: Trends and Developments; European Monitoring Centre for Drugs and Drug Addiction: Lisbon, 2014.

(4) European Drug Report 2017: Trends and Developments; European Monitoring Centre for Drugs and Drug Addiction: Lisbon, 2017.

(5) European Drug Report 2018: Trends and Developments; European Monitoring Centre for Drugs and Drug Addiction: Lisbon, 2018.

(6) Valente, M. J.; Guedes de Pinho, P.; de Lourdes Bastos, M.; Carvalho, F.; Carvalho, M. Khat and synthetic cathinones: a review. Arch. Toxicol. 2014, 88, 15-45.

(7) Smith, J. P.; Sutcliffe, O. B.; Banks, C. E. An overview of recent developments in the analytical detection of new psychoactive substances (NPSs). Analyst 2015, 140, 4932-4948.

(8) Sanchez, S. Sur un homologue de l'ephedrine. Bull. Soc. Chim. Fr. 1929, 45, 284-286.

(9) German, C. L.; Fleckenstein, A. E.; Hanson, G. R. Bath salts and synthetic cathinones: an emerging designer drug phenomenon. Life Sci. 2014, 97, 2-8.

(10) Dargan, P. I.; Sedefov, R.; Gallegos, A.; Wood, D. M. The pharmacology and toxicology of the synthetic cathinone mephedrone (4-methylmethcathinone). Drug Test. Anal. 2011, 3, 454-463.

(11) Report on the Risk Assessment OfMephedrone In The Framework Of The Council Decision On New Psychoactive Substances; The Publications Office of the European Union: Luxembourg, 2011; p 193.

(12) Explanatory Memorandum to The Misuse of Drugs Act 1971 (Amendment) order 2010 No. 1207. http://www.legislation.gov.uk/ uksi/2010/1207/pdfs/uksiem_20101207_en.pdf (accessed November 2018).
(13) Council Decision: Council Decision of 2 December 2010 on submitting 4-methylmethcathinone (mephedrone) to Control Measures (2010/759/EU). https://publications.europa.eu/en/publicationdetail/-/publication/95a5e7de-d1bc-4cb3-ba15-ce96786e88b2/ language-en (accessed November 2018).

(14) US Control of 4-MMC. https://fas.org/sgp/crs/misc/R42066. pdf (accessed May 3, 2016).

(15) Loi, B.; Corkery, J. M.; Claridge, H.; Goodair, C.; Chiappini, S.; Gimeno Clemente, C.; Schifano, F. Deaths of individuals aged 16-24 years in the UK after using mephedrone. Hum. Psychopharmacol. Clin. Exp. 2015, 30, 225-232.

(16) Rojek, S.; Kłys, M.; Maciów-Głąb, M.; Kula, K.; Strona, M. Cathinones derivatives-related deaths as exemplified by two fatal cases involving methcathinone with 4-methylmethcathinone and 4-methylethcathinone. Drug Test. Anal. 2014, 6, 770-777.

(17) Gerace, E.; Petrarulo, M.; Bison, F.; Salomone, A.; Vincenti, M. Toxicological findings in a fatal multidrug intoxication involving mephedrone. Forensic Sci. Int. 2014, 243, 68-73.

(18) Pozo, O. J.; Ibanez, M.; Sancho, J. V.; Lahoz-Beneytez, J.; Farre, M.; Papaseit, E.; de la Torre, R.; Hernandez, F. Mass spectrometric evaluation of mephedrone in vivo human metabolism: identification of phase I and phase II metabolites, including a novel succinyl conjugate. Drug Metab. Dispos. 2015, 43, 248-257.

(19) Pedersen, A. J.; Reitzel, L. A.; Johansen, S. S.; Linnet, K. In vitro metabolism studies on mephedrone and analysis of forensic cases. Drug Test. Anal. 2013, 5, 430-438.

(20) Khreit, O. I. G.; Grant, M. H.; Zhang, T.; Henderson, C.; Watson, D. G.; Sutcliffe, O. B. Elucidation of the Phase I and Phase II metabolic pathways of $( \pm)-4^{\prime}$-methylmethcathinone (4-MMC) and ( \pm )- 4 '(trifluoromethyl)methcathinone (4-TFMMC) in rat liver hepatocytes using LC-MS and LC-MS2. J. Pharm. Biomed. Anal. 2013, 72, 177185 .

(21) Mayer, F. P.; Wimmer, L.; Dillon-Carter, O.; Partilla, J. S.; Burchardt, N. V.; Mihovilovic, M. D.; Baumann, M. H.; Sitte, H. H. Phase I metabolites of mephedrone display biological activity as substrates at monoamine transporters. Br. J. Pharmacol. 2016, 173, 2657-2668.

(22) Olesti, E.; Farre, M.; Papaseit, E.; Krotonoulas, A.; Pujadas, M.; de la Torre, R.; Pozo, O. J. Pharmacokinetics of Mephedrone and Its Metabolites in Human by LC-MS/MS. AAPS J. 2017, 19, 1767-1778.

(23) Concheiro, M.; Castaneto, M.; Kronstrand, R.; Huestis, M. A. Simultaneous determination of 40 novel psychoactive stimulants in urine by liquid chromatography-high resolution mass spectrometry and library matching. J. Chromatogr. A 2015, 1397, 32-42.

(24) Concheiro, M.; Anizan, S.; Ellefsen, K.; Huestis, M. A. Simultaneous quantification of 28 synthetic cathinones and metabolites in urine by liquid chromatography-high resolution mass spectrometry. Anal. Bioanal. Chem. 2013, 405, 9437-9448.

(25) Fontanals, N.; Marce, R. M.; Borrull, F. Solid-phase extraction followed by liquid chromatography-high resolution mass spectrometry to determine synthetic cathinones in different types of environmental water samples. J. Chromatogr. A 2017, 1524, 66-73.

(26) Prosen, H.; Fontanals, N.; Borrull, F.; Marce, R. M. Determination of seven drugs of abuse and their metabolites in surface and wastewater using solid-phase extraction coupled to liquid chromatography with high-resolution mass spectrometry. J. Sep. Sci. 2017, 40, 3621-3631.

(27) Alsenedi, K. A.; Morrison, C. Determination and long-term stability of twenty-nine cathinones and amphetamine-type stimulants (ATS) in urine using gas chromatography-mass spectrometry. J. Chromatogr. B 2018, 1076, 91-102.

(28) Alsenedi, K. A.; Morrison, C. Determination of amphetaminetype stimulants (ATSs) and synthetic cathinones in urine using solid phase micro-extraction fibre tips and gas chromatography-mass spectrometry. Anal. Methods 2018, 10, 1431-1440.

(29) Zuway, K. Y.; Smith, J. P.; Foster, C. W.; Kapur, N.; Banks, C. E.; Sutcliffe, O. B. Detection and quantification of new psychoactive substances (NPSs) within the evolved "legal high" product, NRG-2, 
using high performance liquid chromatography-amperometric detection (HPLC-AD). Analyst 2015, 140, 6283-6294.

(30) Mohamed, M. A.; Atty, S. A.; Yehia, A. M.; Foster, C. W.; Banks, C. E.; Allam, N. K. Electrochemical Determination of the Serotonin Reuptake Inhibitor, Dapoxetine, Using Cesium-Gold Nanoparticles. ACS Omega 2017, 2, 6628-6635.

(31) Smith, J. P.; Sutcliffe, O. B.; Banks, C. E. An overview of recent developments in the analytical detection of new psychoactive substances (NPSs). Analyst 2015, 140, 4932-4948.

(32) Foster, C. W.; Kadara, R. O.; Banks, C. E. Screen-Printing Electrochemical Architectures; Springer International Publishing, 2016.

(33) Mayer, F. P.; Wimmer, L.; Dillon-Carter, O.; Partilla, J. S.; Burchardt, N. V.; Mihovilovic, M. D.; Baumann, M. H.; Sitte, H. H. Phase I metabolites of mephedrone display biological activity as substrates at monoamine transporters. Br. J. Pharmacol. 2016, 173, $2657-2668$.

(34) Blanco, E.; Foster, C. W.; Cumba, L. R.; do Carmo, D. R.; Banks, C. E. Can solvent induced surface modifications applied to screenprinted platforms enhance their electroanalytical performance? Analyst 2016, 141, 2783-2790.

(35) Cumba, L. R.; Foster, C. W.; Brownson, D. A. C.; Smith, J. P.; Iniesta, J.; Thakur, B.; do Carmo, D. R.; Banks, C. E. Can the mechanical activation (polishing) of screen-printed electrodes enhance their electroanalytical response? Analyst 2016, 141, 2791-2799.

(36) Galdino, F. E.; Foster, C. W.; Bonacin, J. A.; Banks, C. E. Exploring the electrical wiring of screen-printed configurations utilised in electroanalysis. Anal. Methods 2015, 7, 1208-1214.

(37) Ruas de Souza, A. P.; Foster, C. W.; Kolliopoulos, A. V.; Bertotti, M.; Banks, C. E. Screen-printed back-to-back electroanalytical sensors: heavy metal ion sensing. Analyst 2015, 140, 4130-4136.

(38) Baciu, T.; Borrull, F.; Calull, M.; Aguilar, C. Enantioselective determination of cathinone derivatives in human hair by capillary electrophoresis combined in-line with solid-phase extraction. Electrophoresis 2016, 37, 2352-2362. 